From these it is clear that five of the cases are in fact true epileptics having fits. In another five or even six, however, there is no more basis for diagnosis of epilepsy than electrocardiograms which are either normal (two cases) or just outside the limits of normal (four cases) together, of course, with an immediate response to phenobarbitone.

The monograph is rounded off by Appendix A. analysing the author's 100 cases of convulsive disorders, and Appendix B which, even more irrelevantly to the main thesis, inadequately discusses the difficult questions whether, and when, convulsions should be treated. At $7 \mathrm{~s}$. this monograph is expensive, tendentious and misleading.

\section{Angiocardiographic Interpretation in Congenital Heart} Disease (American Lecture Series). By Herbert L. Abrams and Henry S. KaPlan. (Pp. viii + 233: 163 figures. 95s.) Oxford: Blackwell Scientific Publications; Springfield. Illinois: Charles C. Thomas. 1956.

This is a comprehensive and excellently illustrated guide to angiocardiography in congenital heart lesions. It is based upon the findings in a large number of cases and is therefore a useful addition to the libraries of all those concerned with the diagnosis of these conditions. It would be of special value to anyone embarking on this branch of radiology for the first time.

There is a good account of the part played by various workers throughout the world in the development of angiocardiography and an adequate bibliography. The technique of the authors is described in detail. Some experienced workers would be less inclined than they to resort to a second injection of dye when the first yields inadequate information, but their mortality rate of only $1 \cdot 5 \%$ perhaps justifies their practice.

A good chapter on normal appearances is followed by a description of the findings in the various congenital abnormalities, the angiocardiographic appearances of each lesion being preceded by a useful summary of the symptoms, signs, electrocardiographic and radiological findings.

The authors are probably correct in their opinion that in future the main scope of this method of investigation will be in congenital heart disease in infants and young children, and as their cases are mostly under 5 years of age this book should continue to be of value.

Surgery of Childhood for Nurses. By RAYMOND FARROw. (Pp. 314: 142 figures. 25s.) Edinburgh and London: E. \& S. Livingstone.

A rapid look through this book with its admirable illustrations and printing on excellent paper makes one look forward with anticipation to reading it. This pleasure is not borne out in practice. There has been considerable carelessness in proof reading. Principle appears on three occasiors instead of principal. Items in the index are not in alphabetical order and such an obvious error as 'frurinary' has not been spotted. The frequency of plural subjects with singular verbs and vice versa is considerable. There has also been a certain carelessness in presentation, for example, 'In infancy the amount given at each feed should be calculated on the basis of $2 \frac{1}{2}$ ounces per pound of body-weight'. It is possible that most readers will appreciate that the author meant $2 \frac{1}{2}$ ounces per pound of body-weight per twentyfour hours. Again, in the part on intravenous infusion, no mention is made of how the nurse should change the bottle, of the danger of air embolism or of the various types of fluid which may be given. In blood transfusion it is stated that if blood belonging to a person of one group is administered by transfusion to a child of a different group then agglutination will inevitably ensue'. This can only lead to confusion when a nurse discovers that she is giving blood of group $O$ to a patient of a different group. One douts if cystic swellings are invariably due to the persistence of some embryological structure and it seems certain that most nurses will appreciate that the latest antibiotic is not aureomycin. Lymphangitis and lymphadenitis are not even in the index or mentioned in connexion with infection, but are described in the chapter on ear, nose and throat. The want of care in proof reading is illustrated by the sentence regarding fluid replacement in burns: 'You will not be called upon to perform this calculation yourself but you must be aware of the reasons for its administration'.

While it is difficult to distinguish between surgery and nursing the book should have made some mention of the various anaesthetics, of the healing of wounds and of the conduct of wound dressings, removal of stitches, etc.

The book will be acceptable to those who remain undisturbed by frequent errors in English.

Report of the Committee on Maladjusted Children. (6s.) London: H.M. Stationery Office. 1955.

This is the report of the committee of experts, representing many different approaches to the problem, which was set up in 1950 to enquire into the medical, educational and social problems relating to the maladjusted child, with reference to their treatment in the educational system.

The 17 members are unanimous in their report and recommendations, which they admit are not new or revolutionary, as they consider that too little is yet known about maladjustment in children and the ways in which it can be successfully treated to make it possible to generalize, or to suggest ready-made solutions.

They consider that greater efforts should be made to treat the maladjusted child in its own home. with the emphasis being laid on treating the family as a unit. With this end in view, they recommend a great increase in the child guidance services in the next decade, with a vast increase in trained personnel, which they realize will be difficult because of the problems of selection and training, one interesting suggestion being that fully trained paediatricians wishing to train as child psychiatrists should be able to do so without loss of status.

They are concerned that the pre-school child, if maladjusted, is unlikely to receive treatment and recommend 